\title{
Serum glial fibrillary acidic protein as a marker of brain damage in patients after carotid endarterectomy
}

\author{
Marek Ilzecki', Stanislaw Przywara', Joanna Ilzecka², Piotr Terlecki', Aneta Grabarska², \\ Andrzej Stepulak ${ }^{3}$, Shawn Dave ${ }^{4}$, Tomasz Zubilewicz' \\ 'Chair and Department of Vascular Surgery and Angiology, Medical University of Lublin, Poland \\ ${ }^{2}$ Independent Neurological Rehabilitation Unit, Medical University of Lublin, Poland \\ ${ }^{3}$ Chair and Department of Biochemistry and Molecular Biology, Medical University of Lublin, Poland \\ ${ }^{4}$ Hope Medical Institute, Newport News, VA, USA
}

\begin{abstract}
Introduction. Surgical treatment of the extracranial section of internal carotid artery stenosis is an effective method of preventing cerebral ischaemic stroke. However, this surgical procedure may cause vascular brain damage. The aim of the study was to measure glial fibrillary acidic protein (GFAP) as a marker of brain damage in the serum of patients that underwent internal carotid endarterectomy (CEA).
\end{abstract}

Material and methods. This study involved 25 participants who underwent CEA because of internal carotid artery stenosis. Blood samples were taken from each patient at three different times; within 24 hours prior to surgery, 12 hours after the surgery, and 48 hours after the surgery. Serum GFAP levels were measured by a commercially available enzyme-linked immunosorbent assay (ELISA).

Results. The study showed that serum GFAP levels were not statistically different between all the three measurements ( $p>0.05$ ). There was also no statistical significant difference in serum GFAP levels between symptomatic and asymptomatic patients $(p>0.05)$. There was no statistically significant correlation in serum GFAP level 12 and 48 hours after the surgery with the clamping time ( $p>0.05$ ). There was also no significant correlation in the serum GFAP levels with the velocity of blood flow in the internal carotid artery before CEA and after surgery $(p>0.05)$.

Conclusions. The study revealed that CEA does not change serum GFAP levels. Thus, GFAP cannot be a biochemical marker of brain damage after this surgery.

Key words: carotid endarterectomy, glial fibrillary acidic protein, biochemical markers, serum

Acta Angiol 2016; 22, I: I-4

\section{Introduction}

Stroke represents one of the major health public problems worldwide and it is a frequent cause of hospitalization, severe morbidity and the third cause of overall mortality [I].

Surgical treatment of the extracranial section of internal carotid artery stenosis is an effective method of preventing cerebral ischaemic stroke [2]. However, this procedure may cause neurological complications during the perioperative period. Micro embolisms, macro embolisms, and increased or decreased blood flow to the brain as a result of the internal carotid artery endarterectomy (CEA) may lead to ischaemic and/or hyperperfusion brain damage [3-5]. 
Glial fibrillary acidic protein (GFAP) is an intermediate filament III protein uniquely found within astrocytes in the central nervous system, non-myelinating Schwann cells in the peripheral nervous system, and enteric glial cells. GFAP mRNA expression is regulated by several nuclear-receptor hormones, growth factors, and lipopolysaccharides. GFAP gene activation and protein induction appears to play a critical role in astroglial cell activation following central nervous system injuries and neurodegeneration. Astrocytes have a range of control and homeostatic functions in health and disease. The evidence also suggests that following traumatic brain and stroke, GFAP and its breakdown products are rapidly released into biofluids, making it a strong candidate as a biomarker for such neurological disorders [6-8].

Therefore, GFAP may also be biochemical marker of brain damage in patients undergoing CEA. The aim of the study was to investigate GFAP in the serum of patients who underwent CEA.

\section{Material and methods}

The study involved patients hospitalized in the Department of Vascular Surgery and Angiology, Medical University of Lublin, Poland, undergoing CEA due to stenosis of the internal carotid artery. Patients were qualified for surgical treatment according to the guidelines of the ESVS (European Society of Vascular Surgery) based on Doppler studies performed using a Toshiba Aplio 500 camera [9]. Patients with high grade stenotic carotid arteries were identified and measured by using the guidelines set by NASCET (North American Symptomatic Carotid Endarterectomy Trial) [10].

The study group consisted of 25 participants ( 15 male, 10 female) aged from 54 to 88 years with an average of 69 years. Patients with the occlusion of the internal carotid artery were not qualified for surgery and research. The degree of the internal carotid artery stenosis ranged from 60 to $90 \%$. The average clamping time of internal carotid artery during CEA was 8.5 minutes. Conventional CEA was performed under local anaesthesia. Shunt was not used. No complications associated with CEA were observed. The average velocity of blood flow in the internal carotid artery before surgery was $208.4 \mathrm{~cm} / \mathrm{s}$, and after the surgery $89.5 \mathrm{~cm} / \mathrm{s}$. Past medical histories of the subject included 8 patients with previous ischaemic stroke, 7 patients with transient ischaemic attack, and 10 patients with asymptomatic internal carotid artery stenosis. The study criteria disqualified patients with known organic brain damage in the course of various diseases of the nervous system.

Blood samples were taken from each patient from the antecubital vein at three different times; within
24 hours prior to surgery (measurement I), 12 hours after surgery (measurement 2), and 48 hours after surgery (measurement 3). Serum samples were collected into the plastic tubes, centrifuged rapidly, and stored at $-80^{\circ} \mathrm{C}$ until the analysis was performed.

Serum GFAP levels were measured by a commercially available enzyme-linked immunosorbent assay (Human GFAP ELISA Kit, BioVendor — Laboratorni medicina, Brno, Czech Republic).

The nonparametric Wilcoxon, Mann-Whitney and Friedman (analysis of variance) tests were used to examine the differences between the groups. The correlation analysis was performed using the Spearman rank correlation. The GFAP values are expressed in $\mathrm{ng} / \mathrm{mL}$, as median and range. $\mathrm{P}$ values $<0.05$ were considered significant.

The study was approved by the Ethics Committee of Medical University in Lublin (KE-0254/218/20I4).

\section{Results}

The serum GFAP levels were not statistically different between all three measurements; median 0.16 $(0.15-0.17) \mathrm{ng} / \mathrm{mL}$, and $0.16(0.15-0.18) \mathrm{ng} / \mathrm{mL}$, and $0.16(0.15-0.17) \mathrm{ng} / \mathrm{mL}(\mathrm{p}=0.70, \mathrm{p}=0.86$, and $p=0.79$; respectively). Therefore, the lack of this statistical difference was also confirmed by the analysis of variance $(p=0.56)$. The serum GFAP levels are presented in Figure I.

There was no statistically significant difference in serum GFAP levels between symptomatic and asymptomatic patients $(p>0.05)$ (Tab. I).

There was also no statistically significant correlation between serum GFAP level and age of patients $(p=0.17)$.

There was no statistically significant correlation in serum GFAP level 12 and 48 hours after the surgery with the clamping time $(r=-0.36, p=0.07$ and $r=0.18, p=0.37$; respectively).

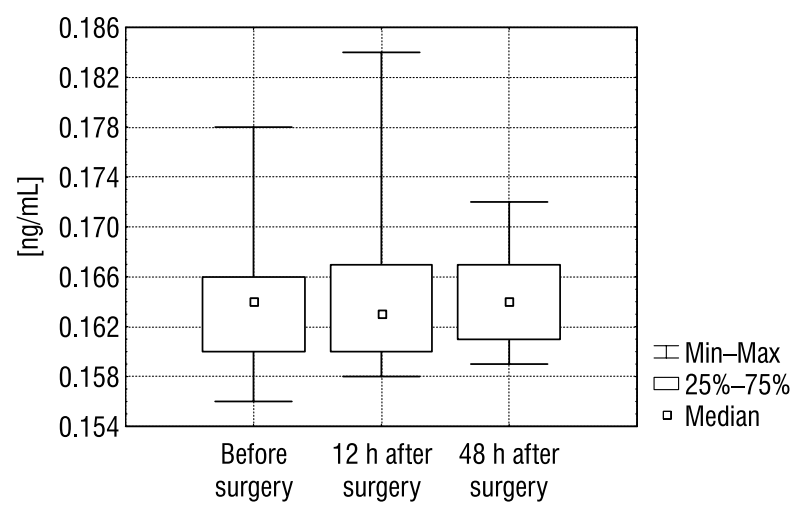

Figure I. Serum glial fibrillary acid protein level in patients 
Table I. Serum glial fibrillary acidic protein levels and a comparative analysis

\begin{tabular}{|l|c|c|c|}
\hline & \multicolumn{2}{c}{ GFAP level [ng/ml] } \\
Measurement & $\begin{array}{c}\text { Symptomatic patients } \\
(\mathrm{n}=15)\end{array}$ & $0.16(0.15-0.17)$ & $\begin{array}{c}\text { Comparison symptomatic } \\
\text { vs. asymptomatic patients }\end{array}$ \\
\hline $\begin{array}{l}\text { Before surgery } \\
\text { (measurement I) }\end{array}$ & $0.16(0.15-0.17)$ & $0.16(0.15-0.18)$ & $\mathrm{p}=0.34$ \\
\hline $\begin{array}{l}\text { I2 h after surgery } \\
\text { (measurement 2) }\end{array}$ & $0.16(0.15-0.17)$ & $0.16(0.16-0.16)$ & $\mathrm{p}=0.76$ \\
\hline $\begin{array}{l}48 \text { h after surgery } \\
\text { (measurement 3) }\end{array}$ & $0.16(0.15-0.17)$ & $\mathrm{p}=0.61$ \\
\hline
\end{tabular}

Data is expressed as median and range. Mann-Whitney test

There was also no significant correlation in the serum GFAP levels with the velocity of blood flow in the internal carotid artery before CEA $(r=-0.34$, $p=0.09)$ and after surgery $(r=0.11, p=0.58$ and $r=0.17, p=0.40$; respectively).

\section{Discussion}

According to Wu et al. [I I] CEA has been proven to be an effective procedure to treat the cerebral ischaemia caused by carotid atherosclerotic stenosis.

Experimental studies showed that cerebral ischaemia promotes changes of the cytoskeleton and activation of apoptosis-related genes, resulting in morphological reactions of neurons, astrocytes, oligodendrocytes, and microglia [12].

There are no studies in the literature concerning serum GFAP level after CEA. Our study showed that serum GFAP level is not changed after surgery. It is difficult to speculate why this specific marker of brain damage is not changed. It can be assumed that glia is less sensitive than the neurons on transient ischaemic/ /hyperperfusion damage during the CEA. Moreover, any increase in the level of serum GFAP can depend on the magnitude of brain damage and its duration. It was observed that serum GFAP level was increased in different neurological diseases with characteristic persistent and chronic brain damage, including multiple sclerosis, glioblastoma, Parkinson disease, traumatic brain injury, and subarachnoid haemorrhage [13-18].

According to Foerch et al. [19], GFAP is a highly brain-specific protein that is expressed in large quantities in astrocytes and has important functions in terms of maintaining and stabilizing the cytoskeleton. Acute intracerebral haemorrhage leads to an immediate mechanical destruction of astroglial cells with the subsequent release of GFAP into the extracellular space and the bloodstream. On the other hand, according to these authors, necrosis, cytolysis, and GFAP release does not occur before 6-12 hours after symptom onset in ischaemic stroke. Thus in the early hours after stroke, increased GFAP values could indicate intracerebral haemorrhage not ischaemia. Serum GFAP analysis performed within 4.5 hours of symptom onset can differentiate intracerebral haemorrhage and ischaemic stroke because GFAP levels are increased in patients with intracerebral haemorrhage compared with patients with ischaemic stroke [20]. GFAP has been reported to have high diagnostic accuracy for differentiating intracerebral haemorrhage from ischaemic stroke in patients within the acute phase of stroke symptom onset [2I].

On the other hand, the study conducted on rats showed that in the ischaemia models, the expression of GFAP indicates early neurodegeneration at 24 hours post-insult [22]. The other authors examined the profile of CSF biomarkers and their relation to stroke severity and degree of white matter lesions. They observed that several CSF biomarkers, including GFAP, also increase in ischaemic stroke, and thus correlate to clinical stroke severity [23]. Brouns et al. [24] investigated CSF levels of different neuromarkers including GFAP in acute ischaemic stroke patients and their relation to initial stroke severity, stroke location, and long-term stroke outcome. They investigated and concluded that biomarkers display relevant differences in cellular and subcellular origins, which are reflected in their relation to stroke characteristics. GFAP correlated with stroke severity and outcome. The study conducted by Wunderlich et al. [25] on serum of patients with ischaemic stroke revealed that GFAP levels are increased from admission onward with the highest levels 48 hours after stroke onset. GFAP release was highly correlated with severity of neurologic deficits and infarct volume.

While in another study, Mayer et al. [26] observed that most acute and chronic neurological diseases are not associated with detectable GFAP levels in the bloodstream. Their data confirms the hypothesis that rapid astroglial destruction, as in acute intracerebral haemorrhage, is mandatory for GFAP increase. Ac- 
cording to our study, short duration of brain ischaemia/ /hyperperfusion during uncomplicated CEA may not cause astroglial destruction and therefore no relevant elevation of GFAP in serum of patients.

\section{Conclusions}

Our study showed that CEA does not change serum GFAP levels. Thus, GFAP cannot be a biochemical marker of brain damage after this surgery.

\section{Acknowledgement}

The study was funded by the Foundation for the Development of Vascular Surgery at the Department of Vascular Surgery and Angiology, Medical University of Lublin, Poland.

\section{Conflict of interests}

The authors declare no conflict of interest.

\section{References}

I. Bejot Y, Benatru I, Rouaud O et al (2007) Epidemiology of stroke in Europe: geographic and environmental differences. J Neurol Sci; 262: 85-88.

2. Pyshkina LI, Khatagova DT, Kabanov AA, Darvish NA, Alibekova ZM (2014) Surgical prevention of stroke in patients with carotid stenosis. Zh Nevrol Psikhiatr Im S S Korsakova; I 14: I4-19.

3. Gupta N, Corriere MA, Dodson TF et al (20II) The incidence of microemboli to the brain is less with endarterectomy than with percutaneous revascularization with distal filters or flow reversal. J Vasc Surg; 53: 316-322.

4. Backhaus R, Boy S, Fuchs K, Ulrich B, Schuierer G, Schlachetzki F (2013) Hyperperfusion syndrome after MCA embolectomy - a rare complication? Am J Case Rep; 14: 513-517.

5. Ballesteros-Pomar M, Alonso-Argüeso G, Tejada-García J, Vaquero-Morillo $\mathrm{F}$ (2012) Cerebral hyperperfusion syndrome in carotid revascularization surgery. Rev Neurol; 55: 490-498.

6. Yang Z, Wang KK (2015) Glial fibrillary acidic protein: from intermediate filament assembly and gliosis to neurobiomarker. Trends Neurosci; 38: 364-374.

7. Petzold A (2015) Glial fibrillary acidic protein is a body fluid biomarker for glial pathology in human disease. Brain Res; 1600: 17-31.

8. Hol EM, Pekny M (20I5) Glial fibrillary acidic protein (GFAP) and the astrocyte intermediate filament system in diseases of the central nervous system. Curr Opin Cell Biol; 32: 121-130.

9. Liapis CD, Bell PR, Mikhailidis D et al (2009) ESVS guidelines. Invasive treatment for carotid stenosis: indications, techiques. Eur J Vasc Endovasc Surg; 37 (4 Suppl): I-19.

10. Staikov IN, Arnold M, Mattle HP et al (2000) Comparison of the ECST, CC, and NASCET grading methods and ultrasound for assessing carotid stenosis. European Carotid Surgery Trial. North American Symptomatic Carotid Endarterectomy Trial G. J Neurol; 247: 68I-686.
II. Wu LF, Lai ZC, Liu CW, Li TJ, Liu B (2013) Advances in the biochemical markers of complications associated with carotid endarterectomy. Zhongguo Yi Xue Ke Xue Yuan Xue Bao; 35: 357-36I.

12. Sukawara T, Lewen A, Noshita N, Gasche Y, Chan PH (2002) Effects of global ischemia duration on neuronal, astroglial, oligodendroglial, and microglial reactions in the vulnerable hippocampal CAI subregion in rats. J Neurotrauma; 19: 85-98.

13. Burman J, Zetterberg H, Fransson M, Loskog AS, Raininko R, Fagius J (2014) Assessing tissue damage in multiple sclerosis: a biomarker approach. Acta Neurol Scand; 130: 8I-89.

14. Lyubimova NV, Toms MG, Fu RG, Bondarenko YV (2013) Biochemical markers of brain tumours. Klin Lab Diagn; 10: 71-72.

15. Su W, Chen HB, Li SH, Wu DY (2012) Correlational study of the serum levels of the glial fibrillary acidic protein and neurofilament proteins in Parkinson's disease patients. Clin Neurol Neurosurg; 1 14: 372-375.

16. Di Pietro V, Amorini AM, Lazzarino G et al (2015) SIOOB and glial fibrillary acidic protein as indexes to monitor damage severity in an in vitro model of traumatic brain injury. Neurochem Res; 40: 991-999.

17. Papa L, Silvestri S, Brophy GM et al (2014) GFAP out-performs SI00 in detecting traumatic intracranial lesions on computed tomography in trauma patients with mild traumatic brain injury and those with extracranial lesions. J Neurotrauma; 31: 1815-1822.

18. Nylén K, Csajbok LZ, Ost M et al (2007) Serum glial fibrillary acidic protein is related to focal brain injury and outcome after aneurysmal subarachnoid hemorrhage. Stroke; 38: 1489-1494.

19. Foerch C, Pfeilschifter W, Zeiner P, Brunkhorst R (2014) Glial fibrillary acidic protein in patients with symptoms of acute stroke: diagnostic marker of cerebral hemorrhage. Nervenarzt; 85 : 982-989.

20. Foerch C, Niessner M, Back T et al (2012) BE FAST Study Group. Diagnostic accuracy of plasma glial fibrillary acidic protein for differentiating intracerebral hemorrhage and cerebral ischemia in patients with symptoms of acute stroke. Clin Chem; 58: 237-245.

21. Zhang J, Zhang CH, Lin XL, Zhang Q, Wang J, Shi SL (2013) Serum glial fibrillary acidic protein as a biomarker for differentiating intracerebral hemorrhage and ischemic stroke in patients with symptoms of acute stroke: a systematic review and metaanalysis. Neurol Sci; 34: 1887-1892.

22. Céspedes AE, Arango CA, Cardona GP (2013) Injury markers in two models of cerebral ischemia. Biomedica; 33: 292-305.

23. Hjalmarsson C, Bjerke M, Andersson B et al (2014) Neuronal and glia-related biomarkers in cerebrospinal fluid of patients with acute ischemic stroke. J Cent Nerv Syst Dis; 6: 5I-58.

24. Brouns R, De Vil B, Cras P, De Surgeloose D, Mariën P, De Deyn PP (2010) Neurobiochemical markers of brain damage in cerebrospinal fluid of acute ischemic stroke patients. Clin Chem; 56: 45 I-458.

25. Wunderlich MT, Wallesch CW, Goertler M (2006) Release of glial fibrillary acidic protein is related to the neurovascular status in acute ischemic stroke. Eur J Neurol; 13: | | | 8-| | 23.

26. Mayer CA, Brunkhorst R, Niessner M, Pfeilschifter W, Steinmetz H, Foerch C (2013) Blood levels of glial fibrillary acidic protein (GFAP) in patients with neurological diseases. PLoS One; 8: e62 I0I. 